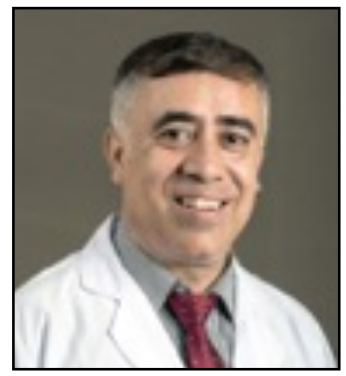

\title{
Professionalism in Medical Education: Where Are We?
}

\section{Dr Hem Sagar Rimal}

The importance of professionalism in the field of medicine in Nepal is highlighted worryingly often in the terrifying news articles that shower the public with accounts of malpractice and unprofessional behaviour, contributing to the growing rift between patients and medical professionals. We need to look back at our undergraduate and post graduate training program to try to answer two very important but often overlooked questions : Whether professionalism has been sufficiently integrated in Medical Education or not and if yes, is the mode of delivery of this concept efficient enough? More importantly, are we assessing this important competency and are we making sure that it is being acquired by our doctors? The focus on professionalism in medicine, and medical education, has developed in response to possible malevolence towards patients on the part of doctors that are inept in dealing with the humanities of medicine.

Professionalism has six important inbuilt elements viz. altruism, accountability, duty, honour or integrity, excellence and respect for others. The physician-patient relationship is the reflection of professionalism and it is central to the delivery of high-quality medical care; it has been shown to affect patient satisfaction as well as a variety of other biological, psychological and social outcomes. ${ }^{1}$ All these professional behaviours and attitudes must be developed during the acquisition of medical education. Hence, it is crucial to make sure that the medical graduates are well aware of, and meet the principles of professional practice i.e. maintaining good clinical practice, successful relationship with patients/parents and effective team work with colleagues.

Yes, professionalism has always been a backbone of medical education. Since the earliest days of medical practices, the professionalism of a doctor has been valued almost as much as their intellect. So, medical education has always gone hand in hand with the principles of professionalism. Throughout medical education, professionalism has been taught almost exclusively through faculty role modelling but with the advancements of medical education, it seems almost irresponsible to leave the inculcation of professionalism at such primitive standards. Medical institutions can no longer rely on the intuition of their faculty to instil professionalism solely through their actions. It is now up to medical institutions to apply standardised

DOI: http://dx.doi.org/10.3126/mjsbh.v17i2.20467

Submitted on: $2018-06-20$

Accepted on: 2018-06-26 
methods to adequately gauge professionalism in their students. It is now up to us to absolutely guarantee that professionalism has not only been taught but actually instilled in our students. It is high time that professionalism becomes an integral part of the curriculum.

Medicine is a community based discipline. Without a sound doctor/patient relationship in the society, neither the patient nor the doctor can get his/her point across. Communication is of paramount importance in medicine and is the essence of diagnosis and treatment. A community that isn't compliant to and supportive of medical professionals further exacerbates the existing insufficiencies in the health of the society. This worrying trend is a red flag for emerging medical educationists and curriculum designers around the nation. Without early intervention in the foundations of medical education in our nation, we risk tarnishing the reputation that the medical profession has garnered because of the social goodwill associated with it. Appropriate attitude, aptitude and knowledge are all equally important aspects that a physician must posses.

Professionalism should be viewed at three different levels. At individual level attributes, capacities and behaviours are considered. The next consideration is interpersonal domain that focusses on teacher student interactions in different contexts. Professionalism is implied at societal and institutional level where notions such as social responsibility and morality but also political agendas and economic imperatives reside. Furthermore, there are interactions amongst these all three domains/levels. For example, an individual's professional behaviour may be influenced by the context; similarly, the individual within an institution may influence its collective professional values to the others. ${ }^{2}$

Teaching professionalism: It is quite a difficult task. The question "How to teach professionalism in medical school?" is even more difficult to answer. There is no concrete method nor is there a blueprint to a sure fire solution. Role modelling and mentoring are important ways of imparting concept of professionalism during medical training but these merely are not enough to guarantee results. Thus, professionalism must be integrated directly into the syllabus for there to be a noticeable change. There is a need for didactic lectures too. Although they may seem primitive, a didactic lecture on professionalism will give medical students something to think about. Without cognitive stimulation on a certain topic, it sometimes becomes harder to grasp, no matter the amount of role models they may be surrounded by. In years one and two of undergraduate training, medical ethics, importance of professionalism, related laws can be taught as a cognitive component. In year three and four, the application part could be taught as case presentations, reflections and portfolio. During internship and post graduation, it should be through more complicated cases and through journal clubs.

Assessment of professionalism: For the immense significance that professionalism possesses in medical education, the assessment hasn't followed suit. Merely including professionalism in the syllabus is not nearly enough. Research has shown that 'that which is not assessed is never learnt.' Therefore it is extremely essential for appropriate assessment tools to be integrated in the curriculum that can gauge the professionalism of our medical students. Professionalism should be assessed longitudinally right from the beginning until internship period and even beyond. It requires combinations of different approaches and at different levels including but not limited to professionalism at individual, interpersonal and institutional/ societal levels. 
Some of the components of professionalism are related to the inherent personality traits. Assessment of these traits (cognitive, personality, behaviours) prior to admission may be relevant to later professionalism aspect of the medical graduates. There are several assessment tools like observed clinical encounter (Mini-CEX, PMEX), collated views of co-workers (360 degree evaluation), records of incidents of professional lapses (incident reporting form), simulations (cases with ethical dilemma) and patient surveys (patient assessment questionnaire) ${ }^{3}$

Without professionalism we cannot call ourselves professionals. It seems that nowadays, many of us are really not. There is a huge lack of professionalism in medical education right now, and this must change if we are to continue to produce true medical professionals. What we need now is an absolute paradigm shift in our attitudes towards the ethical competency of our medical practitioners and focus on the ethical side of our education system as well as the technical side.

\section{REFERENCES}

1. Haidet P, Dains JE, Paterniti DA, Hechtel L, Chang T, Tseng E, et al. Medical student attitudes toward the doctor-patient relationship. Medical education. 2002;36(6):568-74.

DOI: https://doi.org/10.1046/j.1365-2923.2002.01233.x PMid:12047673

2. Hodges BD, Ginsburg S, Cruess R, Cruess S, Delport R, Hafferty F, et al. Assessment of professionalism: recommendations from the Ottawa 2010 Conference. Medical teacher. 2011;33(5): 354-63.

DOI: https://doi.org/10.3109/0142159X.2011.577300ＰMid:21517683

3. Goldie J. Assessment of professionalism: A consolidation of current thinking. Medical teacher. 2013;35(2):952-6.

DOI: https://doi.org/10.3109/0142159X.2012.714888ＰMid:22938675

Professor Dr Hem Sagar Rimal

MBBS, MD (Paediatrics), MPH, Fellowship in Development Paediatrics

Department of Paediatrics

Birat Medical College and Teaching Hospital

Tankisinuwari-02, Morang

Email: hemrimal@gmail.com 